\title{
THERMAL STRESSES AT THE OCEANIC-CONTINENTAL MARGIN
}

\author{
Henry N. POLLACK \\ Department of Geology and Mineralogy, and Geophysics Laboratory, \\ The University of Michigan, Ann Arbor, Michigan, USA
}

Received 20 January 1967

\begin{abstract}
Dissimilar temperature profiles beneath oceans and continents give rise to thermoelastic stresses at and adjacent to the oceanic-continental margin. Computations of the magnitude and orientation of the maximum shear stress field reveal a zone of shear dipping beneath the continent from the margin.
\end{abstract}

One of the important observations emerging from the many recent measurements of the terrestrial heat flux is that, on the average, the amount of heat conducted to the surface of the earth from the interior is about the same in both continental and oceanic regions. The implications of this nearly uniform surface flux are significant. The continental crust has a greater thickness, and, at least near the surface, has a far greater abundance of the heat producing radioactive elements than does the oceanic crust. If we attribute most of the present flux to radiogenic heat production, we are led to infer that much of the oceanic heat is produced at somewhat greater depths than is the continental heat. This in turn implies that at a specified depth, higher temperatures exist under oceans than under continents.

MacDonald [1] noted that dissimilar temperature profiles under continents and oceans would lead to a concentration of thermoelastic stress at their common margin. His main interest in this respect, however, was in the temporal changes in the elastic field, which give an estimate of the elastic strain energy annually available for earthquakes. In this report I wish to center attention on the instantaneous distribution of the thermal stress and displacements, at and adjacent to the oceanic-continental margin, which arise from the dissimilar temperature profiles in these regions.

The differences in temperature beneath continents and oceans serve as a partial control on the elevation of the continental surface relative to the oceanic surface. While the temperature field of the earth is most assuredly time dependent, the temperature differences between continents and oceans are much less so. An equilib- rium temperature field arising from constant heat production at present rates is rather characteristic of the temperature differences that exist over long periods of the time dependent fields computed by MacDonald. Accordingly, I have obtained temperatures for the thermoelastic analysis by numerically solving

$$
-\operatorname{div}[-K(T) \operatorname{grad} T(x, y, z)]+A(x, y, z)=0,
$$

where $A$ is the local heat production steady at present rates, $K$ the thermal conductivity, and $T$ the temperature. The distribution of heat sources $A(x, y, z)$ follows the continental and oceanic models set forth by Clark and Ringwood [2], each of which yields a surface flux of $1.2 \times 10^{-6} \mathrm{cal} / \mathrm{cm}^{2} \mathrm{sec}$. Of this flux, 0.5 comes from below $400 \mathrm{~km}$ depth.

Using the temperature profile at the continental-oceanic junction as a reference, one finds the continent becomes a center of relative contraction (lower temperatures than margin) and the ocean a center of relative expansion (higher temperatures than margin). These temperature differences are shown in fig. 1. The thermoelastic displacement and stress fields that arise from such a distribution of dilatation can be computed by a convenient method outlined by Mindlin and Cheng [3].

The relative displacement field reveals a general upward displacement on the oceanic side, horizontal displacement at the juncture toward the continent, and downward movement on the continental side. There is an apparent similarity between these displacements and the frequently hypothesized mantle convection. However, the maximum horizontal thermoelastic displacement is only about $1 \mathrm{~km}$, far short of 


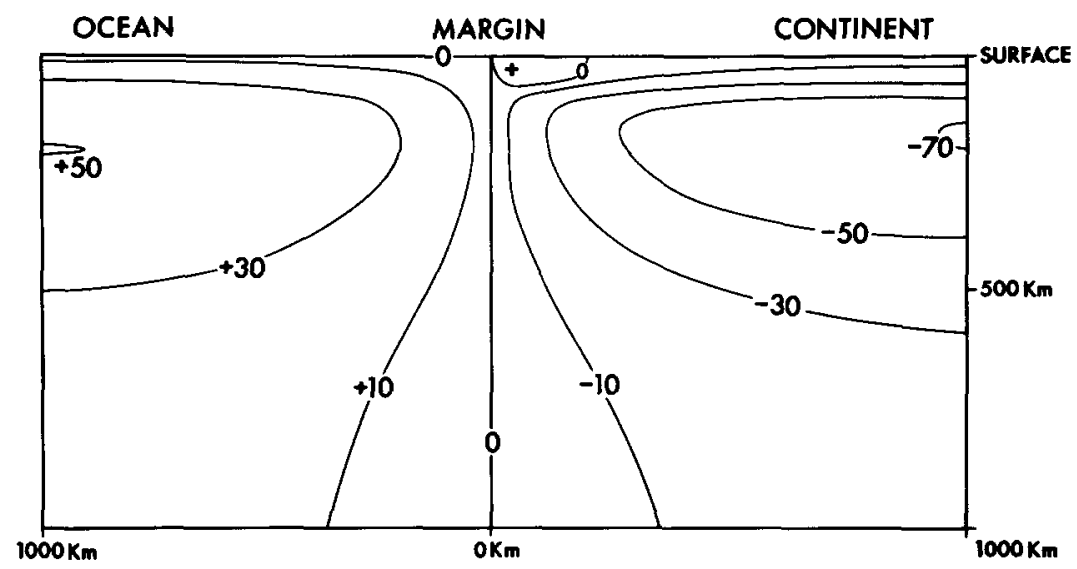

Fig. 1. Temperature at depth beneath continent and ocean relative to temperature at same depth beneath margin. Values shown on contours are in degrees centigrade.

the displacements suggested by convection current advocates. The relative vertical displacement results in a maximum net separation of about $1.4 \mathrm{~km}$, with the oceanic region standing higher. As MacDonald notes, this thermal effect obviously must be offset by phase or compositional differences which elevate the continents above the oceans.

The field of maximum positive shear stress is shown in fig. 2. The field indicates strong normal shearing at the surface of the expanding ocean and strong reverse shearing at the surface of the contracting continent. At long distances from the margin, the magnitudes of these respective shears diminish with depth, each reaching a null at less than $100 \mathrm{~km}$ depth, and thence increasing again but with opposite sense. The shear stress reaches a local maximum at about $200 \mathrm{~km}$, and thereon diminishes regularly with depth in each region.

The null zones that exist beneath mid-continent and mid-ocean do not simply connect at the continental margin. Rather, the continental null zone turns upward and intersects the surface

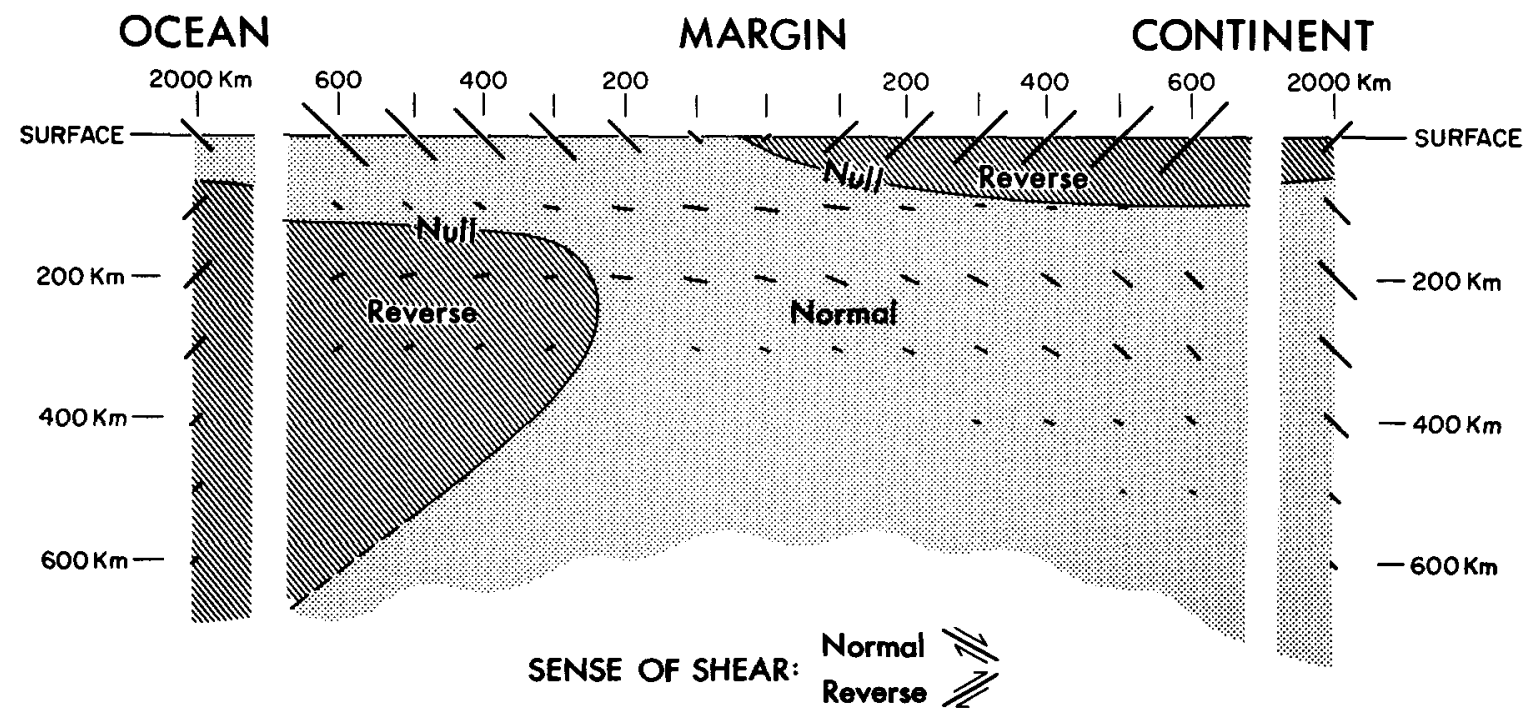

Fig. 2. Field of maximum positive shear stress. The length of a line is proportional to the magnitude of the shear stress; the orientation of a line indicates the dip of the shear plane. The greatest shear stress shown is $1.1 \times 10^{9}$ dynes/ $\mathrm{cm}^{2}$; the others are scaled accordingly. 
quite near the margin. This is the locus of the major circum-Pacific transcurrent faulting, and happily, the thermoelastic field would contribute no dip slip motion there due to the surface null. The zone of normal shear which appears at the surface of the ocean bends downward near the margin to merge with the region of normal shear beneath the null on the continental side. The changing orientation of the maximum shear plane in this zone is also of interest. The dip angle increases from about ten degrees at the margin to forty-five degrees $500 \mathrm{~km}$ inland. The similarity in general features of this zone to the loci of earthquake hypocenters in the circum-Pacific seismicity belt is striking. The sense of the computed shears in this zone is normal. The sense of the circum-Pacific shear at depth is not, however, universally agreed upon; Wilson [4] has suggested normal, and Benioff [5] has suggested reverse.

The maximum thermoelastic shear stress in this model was $1.1 \times 10^{9}$ dynes $/ \mathrm{cm}^{2}$, occurring at the surface of the continent about $600 \mathrm{~km}$ in- land. The magnitude of the shear stress in the zone dipping from the margin beneath the continent is nearly $0.4 \times 10^{9}$ dynes $/ \mathrm{cm}^{2}$ over much of the zone. This stress, though sizeable, is less than the $1.0 \times 10^{9}$ dynes $/ \mathrm{cm}^{2}$ ordinarily considered necessary for faulting. However, as an additional increment to other tectonic stresses, the thermoelastic stress may well be the agent which localizes much crustal instability near the continental margin.

This research was supported by the National Science Foundation under Grant GP-3833.

\section{REFERENCES}

[1] G. J.F. MacDonald, Rev. Geophys. 1 (1963) 587

[2] S. P. Clark Jr. and A.E.Ringwood, Rev. Geophys. 2 (1964) 35 .

[3] R.D. Mindlin and D.H.Cheng, J. Appl. Phys. 21 (1950) 931.

[4] J.T.Wilson, Proc. Geol. Ass. Canada 3 (1950) 141.

[5] H. Benioff, Bull. Geol. Soc. Am. 65 (1954) 385. 